\title{
Studi Efisiensi Hasil Perubahan Sistem Jaringan Irigasi Berbasis SIG (Sistem Informasi Geografis) pada Daerah Irigasi Kajar 2D, Kajar 2E, Kajar 2F, dan Kajar 2G Kecamatan Lowokwaru, Kota Malang
}

\author{
Hanif Rafif ${ }^{*}$, Tri Budi Prayogo ${ }^{1}$ \\ ${ }^{1}$ Jurusan Teknik Pengairan, Fakultas Teknik, Universitas Brawijaya \\ Jalan Mayjen Haryono No.167, Malang, 65145, INDONESIA \\ *Korespondensi Email : hanifrff@gmail.com
}

\begin{abstract}
Referring to the conditions in Lowokwaru sub-district, there was a reduction in the area of rice fields due to an increase in the conversion of paddy fields to residential areas. This study aims to determine changes in the irrigation network system that affect the water distribution system in the irrigation area. This study was conducted using data from 2012 and 2017 which includes a comparative analysis of rice fields using the arc GIS application. analysis of existing irrigation network conditions for comparison of clean water needs of paddy fields. and analysis of the difference in the efficiency of the use of water needs to show whether or not it is still feasible to irrigate the reduced fields due to land use changes in each of the irrigation areas. The results of the study include a comparative analysis of rice fields Area is losing 9\%, losing 7\%, losing $18 \%$ and losing 6\%. Analysis of the difference in efficiency in the use of water needs in each Irrigation Area is an increase of $10.5 \%$, an increase of $24.33 \%$, an increase of $40.55 \%$ and decrease of $34.8 \%$.
\end{abstract}

Keywords: Arc GIS, difference efficience, irrigation, water requirement.
Abstrak: Merujuk kondisi pada Kecamatan Lowokwaru terjadi pengurangan luas areal sawah yang disebabkan meningkatnya alih fungsi lahan sawah menjadi pemukiman penduduk. Studi ini bertujuan mengetahui perubahan sistem jaringan irigasi yang mempengaruhi sistem distribusi air pada D.I .Kajar 2D, 2E, 2F, dan 2G lalu di dadapatkan selisih efisiensi penggunaan air pada D.I. tersebut.
Studi ini dilakukan menggunakan data tahun 2012 dan 2017 yang meliputi analisa perbandingan luasan sawah menggunakan aplikasi Arc GIS. Analisa eksisting kondisi jaringan irigasi untuk perbandingan kebutuhan air bersih sawah. Dan analisa hasil selisih efisiensi penggunaan kebutuhan air untuk menunjukkan masih layak atau tidak untuk mengairi sawah yang berkurang 
karena alih fungsi lahan di tiap D.I. tersebut. Hasil dari studi meliputi analisa perbandingan luas area sawah pada tiap D.I. yaitu kehilangan 9\%, kehilangan $7 \%$,kehilangan $18 \%$ dan kehilangan $6 \%$. Analisa selisih efisiensi penggunaan kebutuhan air pada tiap DI yaitu kenaikan $10.5 \%$, kenaikan $24.33 \%$, kenaikan $40.55 \%$ dan menurun $34.8 \%$.

Kata Kunci: Arc GIS, irigasi, kebutuhan air, selisih efisiensi.

\section{Pendahuluan}

Irigasi menjadi faktor penting dalam produksi pangan. Jaringan irigasi adalah bangunan saluran dan bangunan pelengkap yang merupakan satu kesatuan yang diperlukan untuk penyediaan, pembagian, pemberian, penggunaan dan pembuangan air irigasi [1].

D.I. di Kecamatan Lowokwaru Kota Malang terbagi menjadi 4 yaitu D.I. Kajar 2D, D.I. Kajar 2E, D.I. Kajar 2F dan D.I. Kajar 2G. Peran 4 D.I. ini sangat berpengaruh dalam menyangga kehidupan masyarakat Kota Malang tepatnya di Kecamatan Lowokwaru. 4 DI di Lowokwaru ini merupakan jaringan irigasi yang strategis sebagai penyedia air baku untuk kebutuhan seperti irigasi dan lain-lain .

D.I. Lowokwaru memiliki luas tanam padi antara lain : D.I. Kajar 2D dengan luas tanam padi 1.50 Ha, D.I. Kajar 2E sebesar 30.67 Ha, D.I. Kajar 2F sebesar 15.63 Ha, dan D.I. Kajar $2 \mathrm{G}$ sebesar 22.38 Ha. Jika dibandingkan dengan luas menurut Keputusan Menteri Pekerjaan Umum Nomor 390/KPTS/M/2007 Tentang Penetapan Status Daerah Irigasi Yang Pengelolaannya Menjadi Wewenang Dan Tanggung Jawab Pemerintah Kota Malang mengalami penurunan yang sangat drastis [2].

Penurunan luas area yang ada dikarenakan semakin banyaknya alih fungsi lahan dari lahan pertanian berubah menjadi fungsi pemukiman penduduk atau perumahan. Selain itu juga banyak saluran yang berubah fungsi dari saluran irigasi menjadi saluran pembuang atau drainase. Fakta di lapangan memperlihatkan bahwa saluran D.I. Kajar 2F melewati perkampungan penduduk sehingga secara otomatis memiliki fungsi lain sebagai saluran irigasi juga berfungsi sebagai saluran buangan untuk kebutugan rumah tangga atau drainase dan selain itu juga terjadi kerusakan parah di setiap patok saluran karena pembuatan rumah berada tepat diatas saluran [3].

Mengingat permasalahan yang terjadi dalam wilayah DI Lowokwaru maka perlu dilakukan studi untuk mengetahui perubahan sistem jaringan irigasi (saluran, bangunan irigasi dan luasan sawah) dan sistem distribusi air [4]. Dan juga menggunakan salah satu sistem yang membantu untuk upaya identifikasi areal sawah yang sudah di alih fungsikan menjadi pemukiman atau tidak, yaitu Sistem Informasi Geografis (SIG) yang dapat dipertanggung jawabkan secara teori dan praktis [5]. 


\section{Bahan dan Metode}

\subsection{Lokasi Studi}

Lokasi studi berada pada kecamatan Lowokwaru Kota Malang. Secara geografis Kota Malang berada di Provinsi Jawa Timur, dengan koordinat $112^{\circ} 06^{\prime}-112^{\circ} 07^{\prime}$ Bujur Timur dan $7^{\circ} 06^{\prime}-8^{\circ} 02^{\prime}$ Lintang Selatan.

\subsection{Bahan}

Dalam studi ini diperlukan data sebagai penunjang dalam penyelesaian studi ini, antara lain:

1. Data Inventarisasi saluran primer dan sekunder di D.I. Kajar 2D, D.I. Kajar 2E, D.I. Kajar 2F, D.I. Kajar 2G Kecamatan Lowokwaru Kota Malang.

2. Peta Tata Guna Lahan Tahun 2012 Kota Malang.

3. Data Curah Hujan tahun 2003 - 2017 Kota Malang.

4. Referensi yang berkaitan dengan studi ini.

\subsection{Metode}

1. Melakukan survey ke lapangan (foto dan mengukur), setelah itu data yang didapatkan, direkap sebagai input kondisi saluran dan bangunan pada peta tata guna lahan

2. Mengolah peta rupa bumi Indonesia menjadi peta digital menggunakan aplikasi Arc GIS 10.2,lalu menganalisa dan membandingkan hasil luasan sawah peta digital dari Arc GIS 10.2 dengan peta tata guna lahan 2012

3. Melakukan perhitungan kebutuhan air sawah disetiap DI Kecamatan Lowokwaru Kota Malang pada tahun 2012.

4. Mengevaluasi efisiensi pengunaan air dan juga hasil yang diperoleh dari kondisi system jaringan serta kebutuhan air bersih sawah dan membuat peta tata guna lahan tahun 2017 yang lebih menginformasikan mengenai kondisi saluran dan bangunan irigasi beserta luasan sawah pada tiap Daerah Irigasi

\subsection{Persamaan}

\subsubsection{Analisis Curah Hujan}

\section{A. Uji Konsistensi RAPS}

Hasil pengujian dengan metode RAPS menunjukkan bahwa nilai $(\mathrm{Q} / \mathrm{n})$ 0,5 dan (R / n) 0,5 lebih kecil dari nilai $(\mathrm{Q} / \mathrm{n})$ 0,5 dan $(\mathrm{R} / \mathrm{n})$ 0,5 sebagai nilai statistik. Sehingga dapat disimpulkan bahwa, data curah hujan setiap 10 tahun layak dipakai [6].

$$
\begin{array}{cc}
S * * k=\frac{S * k}{D y} & \text { Pers. 1 } \\
D y^{2}=\frac{\sum_{i}^{k}=1(y i-y)^{2}}{n} & \text { Pers. 2 }
\end{array}
$$

$\mathrm{S}^{* * *} \mathrm{k}=$ nilai konsistensi data

$\mathrm{n}=$ jumlah data

Dy $=$ simpangan rata-rata 


\section{B. Kebutuhan Air Irigasi}

Kebutuhan air disawah untuk tanaman padi ditentukan oleh beberapa faktor yaitu penyiapan lahan, penggunaan konsumtif, perkolasi dan curah hujan efektif (Anonim, 1986) [6]. Besarnya kebutuhan air irigasi menurut metode kriteria perencanaan PU dapat dihitung dengan menggunakan persamaan dibawah ini:

$$
N F R=P L+E T C+P+W L R-R_{e f f} \quad \text { Pers. } 3
$$

NFR $=$ Kebutuhan air bersih di sawah (mm/hari)

$\mathrm{PL}=$ Kebutuhan air untuk penyiapan lahan $(\mathrm{mm} / \mathrm{hari})$

Etc $=$ kebutuhan air tanaman $(\mathrm{mm} / \mathrm{hari})$

$\mathrm{P}=$ Kehilangan air akibat perkolasi ( $\mathrm{mm} / \mathrm{hari})$

$\mathrm{R}_{\mathrm{eff}}=$ Curah hujan efektif ( $\left.\mathrm{mm} / \mathrm{hari}\right)$

WLR = Pergantian lapisan air $(\mathrm{mm} / \mathrm{hari})$

\subsubsection{Evapotranspirasi Metode Penman}

Evapotanspirasi sangat erat berkaitan dengan kebutuhan air tanaman. Evapotanspirasi adalah gabungan dari proses penguapan air bebas (evaporasi) dan penguapan melalui tanaman (transpirasi) [7]. Faktor-faktor yang mempengaruhi evapotranspirasi adalah suhu, kecepatan angin, kelembaban udara, sinar matahari, dan lain-lain (Limantara, 2010). Dalam kajian ini untuk menghitung besarnya evapotranspirasi digunakan metode Penman [8].

$$
\begin{gathered}
\text { Eto }=\text { c.Eto* }{ }^{*} \text { Pers. } 4 \\
\text { Eto }=w(0,75 . R s-R n 1)+(1-w) \cdot f(U) .(\varepsilon \gamma-\varepsilon d) \quad \text { Pers. } 5
\end{gathered}
$$

Dengan:

$\mathrm{Et}_{0}=$ Evaporasi Potensial ( $\left.\mathrm{mm} / \mathrm{hari}\right)$

$\mathrm{c}=$ Angka Koreksi

$\mathrm{Et}_{0}{ }^{*}=$ Evaporasi Potensial sebelum dikoreksi

$\mathrm{w}=$ Faktor yang berhubungan dengan suhu dan elevasi daerah

$\mathrm{Rs}=$ Radiasi gelombang pendek $(\mathrm{mm} / \mathrm{hari})$

Ry $=$ Radiasi gelombang pendek yang memenuhi batas luar atmosfir

$\mathrm{Rn} 1$ = Radiasi bersih gelombang panjang $(\mathrm{mm} / \mathrm{hari})$

$\mathrm{F}(\mathrm{u})=$ Fungsi kecepatan angin pada ketinggian $2.00 \mathrm{~m}$

$(\varepsilon \gamma-\varepsilon d)=$ perbedaan tekanan uap jenuh dengan tekanan uap yang sebenarnya

\subsection{Perhitungan Efisiensi Irigasi}

Efisiensi irigasi adalah perbandingan air dipakai dan air yang disadap dalam persen. Cara perhitungan efisiensi rerata saluran irigasi [9].

$$
\text { ef }=1-\left(\frac{\text { Eair yang diberikan- } \text { - } \text { air digunakan }}{\text { Eair yang diberikan }}\right) \times 100 \% \quad \text { Pers. } 6
$$




\section{Hasil dan Pembahasan}

\subsection{Analisa Tumpang Susun (Overlay)}

Tabel 1. Perbedaan Luas Area Sawah tahun 2012 dan tahun 2017 Pada setiap Daerah Irigasi di Kecamatan Lowokwaru, Kota Malang menggunakan Arc GIS 10.2

\begin{tabular}{llcc}
\hline Kecamatan & Daerah Irigasi & \multicolumn{2}{c}{ Tahun } \\
& & 2012 & 2017 \\
\hline Lowokwaru & Kajar 2D & 1.65 & 1.50 \\
& Kajar 2E & 32.98 & 30.67 \\
& Kajar 2F & 19.09 & 15.63 \\
Jumlah Total Luasan & Kajar 2G & 23.75 & 22.38 \\
\hline
\end{tabular}

Sumber: Hasil Perhitungan

Berdasarkan hasil perbedaan Luas Area Sawah tahun 2012 dan tahun 2017 menggunakan Arc GIS 10.2.2, luas area sawah pada setiap D.I. mengalami penurunan luas area sawah, DI Kajar 2D mengalami penurunan dari total luas lahan sawah tahun 2012 sebesar 1,65 ha menjadi 1,50 ha pada tahun 2017, D.I. Kajar 2E mengalami penurunan dari total luas lahan sawah tahun 2012 sebesar 32.98 ha menjadi 30.67 ha pada tahun 2017 , D.I. Kajar 2F mengalami penurunan dari total luas lahan sawah 2012 sebesar 19.09 ha menjadi 15.63 ha pada tahun 2017, dan D.I. Kajar 2G mengalami penurunan dari total luas lahan sawah 2012 sebesar 23.75 ha menjadi 22.38 ha pada tahun 2017. Banyak dari luasan DI yang berubah diakibatkan karena perubahan lahan sawah yang sekarang sudah menjadi lahan untuk perumahan.

Jadi dapat disimpulkan dari 4 D.I. yang berada di Kecamatan Lowokwaru mengalami penurunan luas area sawah secara keseluruhan. D.I. Kajar 2D kehilangan 0.15 ha atau 9\%, D.I. Kajar 2E kehilangan 2.31 ha atau 7\%, D.I. Kajar 2F kehilangan 3.46 ha atau $18 \%$, dan D.I. Kajar 2G kehilangan 1.37 ha atau 6\% .Urutan D.I. yang kehilangan luas area sawah dari yang sedikit hingga paling besar adalah D.I. Kajar 2D - D.I. Kajar 2G - D.I. Kajar 2E - D.I. Kajar 2F.

\subsection{Kondisi Eksisting Jaringan Irigasi Tahun 2017}

\section{DI Kajar 2D}

A. Bendung masih dalam keadaan baik karena tingkat rusak dibawah $10 \%$ dari keadaan awal bangunan, maka dari itu dibutuhkan pemeliharaan rutin [10].

B. Bangunan Air:

- Bangunan bagi saluran primer Kajar 2D (pintu I) masih dalam keadaan baik karena tingkat rusak dibawah $10 \%$ dari keadaan awal , maka perlu dilakukan pemeliharaan rutin.

- Saluran primer masih dalam keadaan baik karena tingkat rusak dibawah $10 \%$ dari keadaan awal , maka dari itu dibutuhkan pemeliharaan rutin

\section{DI Kajar 2E}

A. Bendung masih dalam keadaan baik karena tingkat kerusakan kurang dari $10 \%$ dari keadaan awal, maka dari itu dibutuhkan pemeliharaan rutin. 
B. Bangunan Air:

- Bangunan bagi saluran primer kajar 2E (pintu I) masih dalam keadaan baik karena tingkat rusak dibawah $10 \%$ dari keadaan awal, maka perlu pemeliharaan rutin.

C. Saluran Primer

- Pada saluran primer patok 10 - 11 dan patok 16-17 pasangan batu pada saluran hancur atau rusak sepanjang saluran sehingga kerusakan lebih dari $40 \%$ dari keadaan awal dan dibutuhkan memperbaiki pada saluran.

\section{DI Kajar 2F}

A. Bendung masih dalam keadaan baik karena tingkat kerusakan dibawah $10 \%$ dari bangunann, maka dari itu dibutuhkan pemeliharaan rutin.

B. Bangunan Air:

- Bangunan bagi saluran primer Kajar 2F (pintu) masih dalam keadaan baik karena tingkat kerusakan kurang dari 10\% dari keadaan awal bangunan, makan diperlukan penjagaan yang rutin.

C. Saluran Primer

- Pada saluran primer patok 18-19 mengalami kerusakan lubang pada saluran sebesar 3m (20\% dari besar saluran) kondisi jaringan baik tingkat kerusakan kurang dari $10 \%$ dari kondisi awal.

- Pada saluran primer patok 25-26 pasangan batu pada saluran hancur atau rusak sepanjang saluran sehingga kerusakan kurang dari $40 \%$ dari kondisi awal dan membutuhkan perbaikan berat atau penggantian pada saluran.

- Pada patok 30 sampai 31 terjadi kehilangan air sehingga tingkat kerusakan antara $21 \%$ sampai $40 \%$ dari kondisi awal saluran dan membutuhkan perbaikan saluran.

- Saluran sekunder masih dalam kondisi baik karena tingkat kerusakan kurang dari $10 \%$ dari kondisi awal bangunan, maka dari itu dibutuhkan pemeliharaan rutin.

\section{DI Kajar 2G}

A. Bendung masih dalam keadaan baik karena tingkat kerusakan dibawah $10 \%$ dari keadaan awal bangunan, maka dari itu dibutuhkan pemeliharaan rutin.

B. Bangunan air

Bangunan bagi saluran primer Kajar 2G (pintu) masih dalam keadaan baik karena tingkat kerusakan kurang dari $10 \%$ dari keadaan awal, makan dibutuhkan pelihara rutin.

C. Saluran primer masih dalam keadaan baik karena tingkat kerusakan dibawah $10 \%$ dari keadaan awal, maka dari itu dibutuhkan pemeliharaan rutin.

D. Saluran sekunder kiri patok 2-3 kondisi jaringan rusak sedang pasangan batu pada saluran hancur atau rusak sepanjang saluran sehingga tingkat rusak antara $21 \%$ sampai40\% dari keadaan awal dan membutuhkan saluran.

\subsection{Kebutuhan Air Bersih Sawah Tahun 2012 dan Tahun 2017}

\subsubsection{Perhitungan Jumlah Kebutuhan Air Irigasi}

Kebutuhan Air Irigasi (pada DI Kajar 2E) [1]. 
$=$ NFR $x$ Luas Lahan / Effisiensi

$=0.993 \times 30.67 /(0.80 \times 0.80 \times 0.38)$

$=125.233 \mathrm{lt} / \mathrm{detik}$

Perbandingan Keb. Air Irigasi Tahun 2012 dan Tahun 2017

DI Kajar 2D

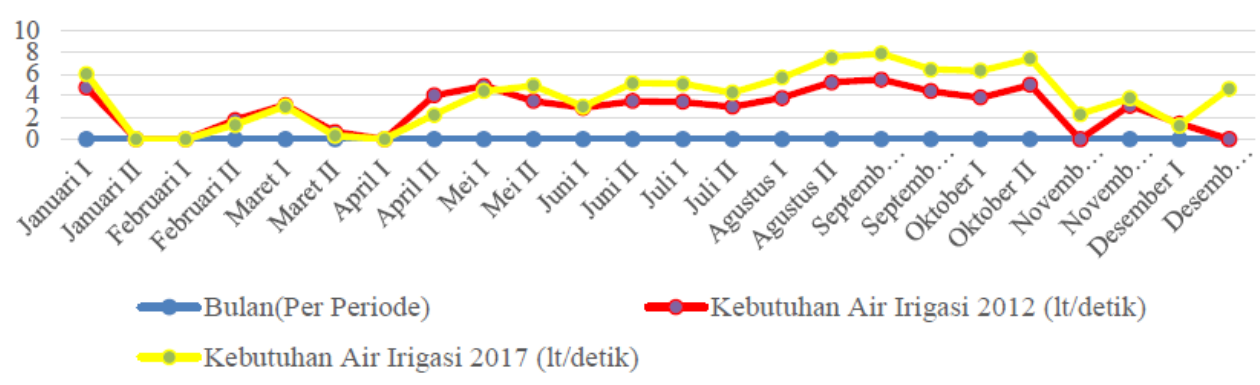

Gambar 1. Perbandingan Kebutuhan Air Irigasi Tahun 2012 dan 2017 DI Kajar 2D

Perbandingan Keb. Air Irigasi Tahun 2012 dan Tahun 2017 DI Kajar 2E

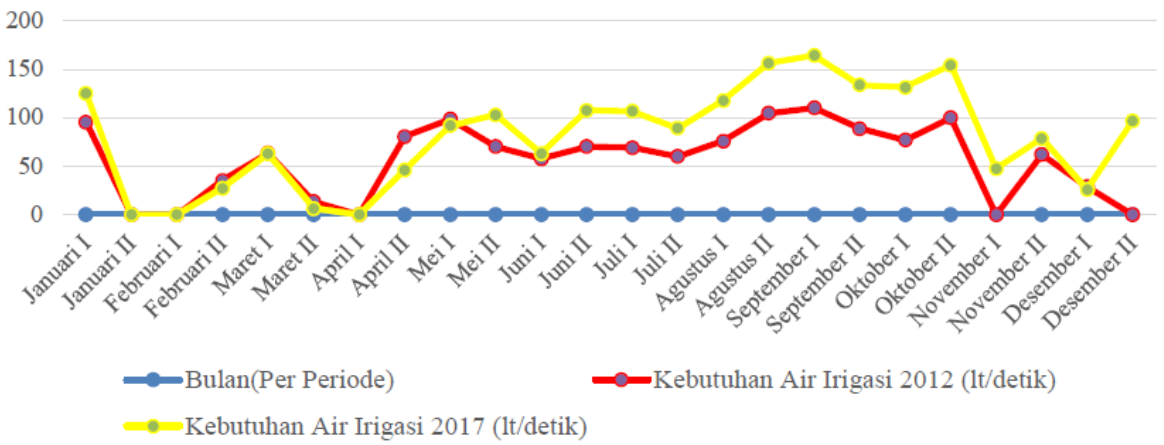

Gambar 2. Perbandingan Kebutuhan Air Irigasi Tahun 2012 dan 2017 DI Kajar 2E

Perbandingan Keb. Air Irigasi Tahun 2012 dan Tahun 2017 DI Kajar 2F

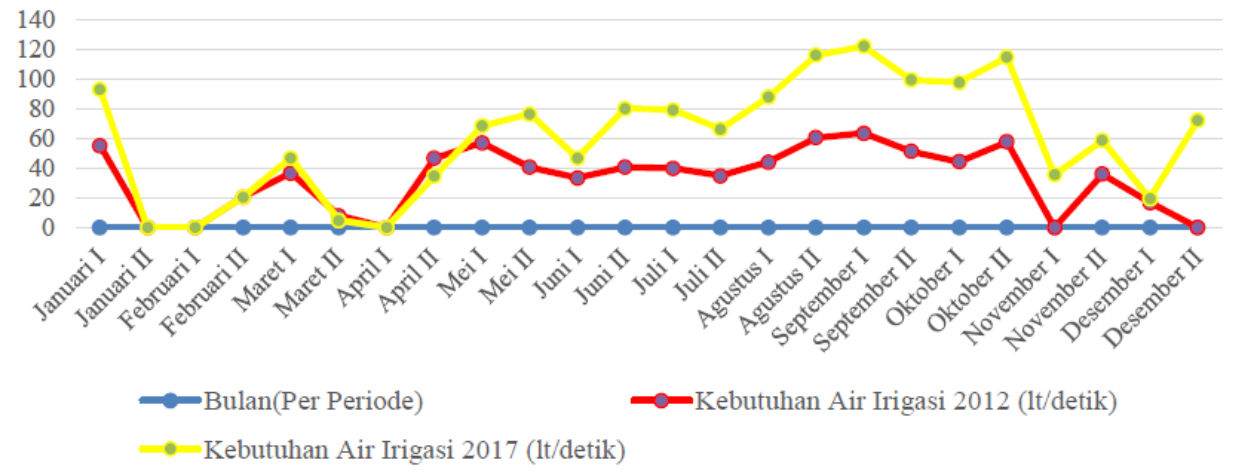

Gambar 3. Perbandingan Kebutuhan Air Irigasi Tahun 2012 dan 2017 DI Kajar 2F 


\section{Perbandingan Keb. Air Irigasi Tahun 2012 dan Tahun 2017 DI Kajar 2G}

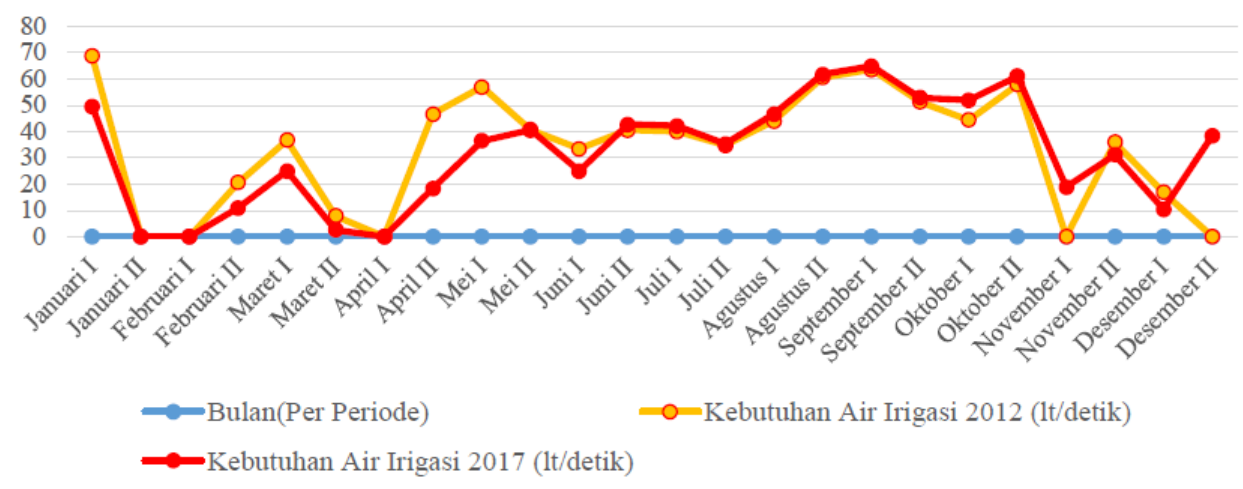

Gambar 4. Perbandingan Kebutuhan Air Irigasi Tahun 2012 dan 2017 DI Kajar 2G

\subsection{Selisih Efisiensi Kebutuhan Air Tahun 2012 dan 2017}

Tabel 2. Selisih efisiensi penggunaan air DI Kajar 2D

\begin{tabular}{|c|c|c|c|c|}
\hline Bulan & Periode & $\begin{array}{c}\text { Kebutuhan Air Irigasi } \\
\mathbf{2 0 1 2} \\
(1 \mathrm{t} / \mathrm{dt})\end{array}$ & $\begin{array}{c}\text { Kebutuhan Air Irigasi } \\
\mathbf{2 0 1 7} \\
(\mathrm{lt} / \mathrm{dt})\end{array}$ & $\begin{array}{l}\text { Selisih efisiensi } \\
\text { penggunaan air }\end{array}$ \\
\hline \multirow[t]{2}{*}{ Januari } & I & 4.776 & 6.032 & $(+20.81 \%)$ \\
\hline & II & 0 & 0 & \\
\hline \multirow{2}{*}{ Februari } & I & 0 & 0 & \\
\hline & II & 1.778 & 1.325 & $(-25.51 \%)$ \\
\hline \multirow[t]{2}{*}{ Maret } & I & 3.172 & 3.03 & $(-4.47 \%)$ \\
\hline & II & 0.683 & 0.314 & $(-54.09 \%)$ \\
\hline \multirow[t]{2}{*}{ April } & I & 0 & 0 & \\
\hline & II & 4.036 & 2.235 & $(-44.63 \%)$ \\
\hline \multirow[t]{2}{*}{ Mei } & I & 4.933 & 4.429 & $(-10.21 \%)$ \\
\hline & II & 3.512 & 4.956 & $(+29.13 \%)$ \\
\hline \multirow{2}{*}{ Juni } & I & 2.892 & 3.039 & $(+4.84 \%)$ \\
\hline & II & 3.509 & 5.187 & $(+32.35 \%)$ \\
\hline \multirow[t]{2}{*}{ Juli } & I & 3.46 & 5.132 & $(+32.57 \%)$ \\
\hline & II & 3.005 & 4.294 & $(+30.02 \%)$ \\
\hline \multirow[t]{2}{*}{ Agustus } & I & 3.809 & 5.682 & $(+32.96 \%)$ \\
\hline & II & 5.236 & 7.519 & $(+30.36 \%)$ \\
\hline \multirow[t]{2}{*}{ September } & I & 5.506 & 7.903 & $(+30.34 \%)$ \\
\hline & II & 4.437 & 6.438 & $(+31.08 \%)$ \\
\hline \multirow[t]{2}{*}{ Oktober } & I & 3.845 & 6.326 & $(+39.22 \%)$ \\
\hline & II & 5.005 & 7.427 & $(+32.61 \%)$ \\
\hline \multirow[t]{2}{*}{ November } & I & 0 & 2.298 & $(+100 \%)$ \\
\hline & II & 3.108 & 3.796 & $(+18.12 \%)$ \\
\hline \multirow[t]{2}{*}{ Desember } & I & 1.457 & 1.26 & $(-13.48 \%)$ \\
\hline & II & 0 & 4.671 & $(+100 \%)$ \\
\hline Total & & 68.159 & 93.293 & $(+26.94 \%)$ \\
\hline
\end{tabular}

Berdasarkan perhitungan berikut pada DI Kajar 2D mengalami kenaikan kebutuhan air, luasan areal sawah berkurang, dan saluran masih berfungsi dengan baik. 
Tabel 3. Selisih efisiensi penggunaan air DI Kajar 2E

\begin{tabular}{|c|c|c|c|c|}
\hline Bulan & Periode & $\begin{array}{c}\text { Kebutuhan Air Irigasi } \\
\mathbf{2 0 1 2} \\
(\mathrm{lt} / \mathrm{dt}) \\
\end{array}$ & $\begin{array}{c}\text { Kebutuhan Air Irigasi } \\
\text { 2017 } \\
(1 \mathrm{t} / \mathrm{dt}) \\
\end{array}$ & $\begin{array}{l}\text { Selisih efisiensi } \\
\text { penggunaan air }\end{array}$ \\
\hline \multirow[t]{2}{*}{ Januari } & I & 95.468 & 125.233 & $(+23.77 \%)$ \\
\hline & II & 0 & 0 & \\
\hline \multirow[t]{2}{*}{ Februari } & I & 0 & 0 & \\
\hline & II & 35.54 & 27.502 & $(-22.62 \%)$ \\
\hline \multirow[t]{2}{*}{ Maret } & I & 63.405 & 62.916 & $(-0.77 \%)$ \\
\hline & II & 13.654 & 6.511 & $(-52.31 \%)$ \\
\hline \multirow[t]{2}{*}{ April } & I & 0 & 0 & \\
\hline & II & 80.669 & 46.395 & $(-42.49 \%)$ \\
\hline \multirow[t]{2}{*}{ Mei } & I & 98.593 & 91.957 & $(-6.73 \%)$ \\
\hline & II & 70.199 & 102.89 & $(+31.77 \%)$ \\
\hline \multirow[t]{2}{*}{ Juni } & I & 57.811 & 63.108 & $(+8.39 \%)$ \\
\hline & II & 70.145 & 107.707 & $(+34.87 \%)$ \\
\hline \multirow[t]{2}{*}{ Juli } & I & 69.167 & 106.55 & $(+38.08 \%)$ \\
\hline & II & 60.059 & 89.154 & $(+32.63 \%)$ \\
\hline \multirow[t]{2}{*}{ Agustus } & I & 76.136 & 117.968 & $(+35.46 \%)$ \\
\hline & II & 104.659 & 156.122 & $(+32.96 \%)$ \\
\hline \multirow[t]{2}{*}{ September } & I & 110.044 & 164.095 & $(+32.94 \%)$ \\
\hline & II & 88.687 & 133.67 & $(+33.65 \%)$ \\
\hline \multirow[t]{2}{*}{ Oktober } & I & 76.848 & 131.345 & $(+41.49 \%)$ \\
\hline & II & 100.039 & 154.21 & $(+35.13 \%)$ \\
\hline \multirow[t]{2}{*}{ November } & I & 0 & 47.714 & $(+100 \%)$ \\
\hline & II & 62.121 & 78.806 & $(+21.17 \%)$ \\
\hline \multirow[t]{2}{*}{ Desember } & I & 29.114 & 26.167 & $(-10.12 \%)$ \\
\hline & II & 0 & 96.993 & $(+100 \%)$ \\
\hline Total & & 1362.358 & 1937.012 & $(+29.68 \%)$ \\
\hline
\end{tabular}

Berdasarkan perhitungan berikut pada DI Kajar 2E mengalami kenaikan kebutuhan air, luasan areal sawah berkurang, dan ada beberapa kerusakan disaluran.

Tabel 3. Selisih efisiensi penggunaan air DI Kajar 2F

\begin{tabular}{|c|c|c|c|c|}
\hline Bulan & Periode & $\begin{array}{c}\text { Kebutuhan Air Irigasi } \\
2012 \\
(1 \mathrm{t} / \mathrm{dt})\end{array}$ & $\begin{array}{c}\text { Kebutuhan Air Irigasi } \\
\text { 2017 } \\
(1 \mathrm{t} / \mathrm{dt})\end{array}$ & $\begin{array}{l}\text { Selisih efisiensi } \\
\text { penggunaan air }\end{array}$ \\
\hline \multirow[t]{2}{*}{ Januari } & $\mathrm{I}$ & 55.26 & 93.277 & $(+40.76 \%)$ \\
\hline & II & 0 & 0 & \\
\hline \multirow[t]{2}{*}{ Februari } & I & 0 & 0 & \\
\hline & II & 20.572 & 20.484 & $(-0.43 \%)$ \\
\hline \multirow{2}{*}{ Maret } & I & 36.701 & 46.861 & $(+21.69 \%)$ \\
\hline & II & 7.903 & 4.85 & $(-38.64 \%)$ \\
\hline \multirow[t]{2}{*}{ April } & I & 0 & 0 & \\
\hline & II & 46.694 & 34.556 & $(-25.99 \%)$ \\
\hline \multirow[t]{2}{*}{ Mei } & I & 57.069 & 68.492 & $(+16.68 \%)$ \\
\hline & II & 40.634 & 76.636 & $(+46.98 \%)$ \\
\hline \multirow[t]{2}{*}{ Juni } & I & 33.463 & 47.004 & $(+28.81 \%)$ \\
\hline & II & 40.602 & 80.223 & $(+49.39 \%)$ \\
\hline \multirow{2}{*}{ Juli } & I & 40.036 & 79.361 & $(+49.55 \%)$ \\
\hline & II & 34.765 & 66.404 & $(+47.65 \%)$ \\
\hline \multirow[t]{2}{*}{ Agustus } & I & 44.07 & 87.866 & $(+49.84 \%)$ \\
\hline & II & 60.581 & 116.284 & $(+47.90 \%)$ \\
\hline \multirow[t]{2}{*}{ September } & I & 63.698 & 122.222 & $(+47.88 \%)$ \\
\hline & II & 51.335 & 99.561 & $(+48.44 \%)$ \\
\hline
\end{tabular}




\begin{tabular}{|c|c|c|c|c|}
\hline Bulan & Periode & $\begin{array}{c}\text { Kebutuhan Air Irigasi } \\
2012\end{array}$ & $\begin{array}{c}\text { Kebutuhan Air Irigasi } \\
2017\end{array}$ & $\begin{array}{l}\text { Selisih efisiensi } \\
\text { penggunaan air }\end{array}$ \\
\hline \multirow{2}{*}{ Oktober } & I & 44.482 & 97.829 & $(+54.53 \%)$ \\
\hline & II & 57.906 & 114.86 & $(+49.59 \%)$ \\
\hline \multirow{2}{*}{ November } & I & 0 & 35.539 & $(+100 \%)$ \\
\hline & II & 35.958 & 58.697 & $(+38.74 \%)$ \\
\hline \multirow[t]{2}{*}{ Desember } & I & 16.852 & 19.49 & $(+13.53 \%)$ \\
\hline & II & $\frac{0}{788.581}$ & $\begin{array}{c}72.243 \\
1442.739\end{array}$ & $\frac{(+100 \%)}{(+45.34 \%)}$ \\
\hline
\end{tabular}

Berdasarkan perhitungan berikut pada DI Kajar 2F mengalami kenaikan kebutuhan air, luasan areal sawah berkurang, dan ada beberapa kerusakan disaluran.

Tabel 3. Selisih efisiensi penggunaan air DI Kajar 2G

\begin{tabular}{|c|c|c|c|c|}
\hline Bulan & Periode & $\begin{array}{c}\text { Kebutuhan Air Irigasi } \\
2012 \\
(1 \mathrm{t} / \mathrm{dt})\end{array}$ & $\begin{array}{l}\text { Kebutuhan Air } \\
\text { Irigasi } 2017 \\
\text { (lt/dt) }\end{array}$ & $\begin{array}{l}\text { Selisih efisiensi } \\
\text { penggunaan air }\end{array}$ \\
\hline \multirow[t]{2}{*}{ Januari } & I & 68.75 & 49.608 & $(-27.84 \%)$ \\
\hline & II & 0 & 0 & \\
\hline \multirow[t]{2}{*}{ Februari } & I & 0 & 0 & \\
\hline & II & 20.572 & 10.894 & $(-47.04 \%)$ \\
\hline \multirow[t]{2}{*}{ Maret } & I & 36.701 & 24.923 & $(-32.09 \%)$ \\
\hline & II & 7.903 & 2.579 & $(-67.37 \%)$ \\
\hline \multirow[t]{2}{*}{ April } & I & 0 & 0 & \\
\hline & II & 46.694 & 18.378 & $(-60.64 \%)$ \\
\hline \multirow{2}{*}{ Mei } & I & 57.069 & 36.426 & $(-36.17 \%)$ \\
\hline & II & 40.634 & 40.757 & $(+0.30 \%)$ \\
\hline \multirow[t]{2}{*}{ Juni } & I & 33.463 & 24.999 & $(-25.29 \%)$ \\
\hline & II & 40.602 & 42.665 & $(+4.84 \%)$ \\
\hline \multirow[t]{2}{*}{ Juli } & I & 40.036 & 42.207 & $(+5.14 \%)$ \\
\hline & II & 34.765 & 35.316 & $(+1.56 \%)$ \\
\hline \multirow[t]{2}{*}{ Agustus } & I & 44.07 & 46.73 & $(+5.69 \%)$ \\
\hline & II & 60.581 & 61.844 & $(+2.04 \%)$ \\
\hline \multirow{2}{*}{ September } & I & 63.698 & 65.002 & $(+2.01 \%)$ \\
\hline & II & 51.335 & 52.95 & $(+3.05 \%)$ \\
\hline \multirow[t]{2}{*}{ Oktober } & I & 44.482 & 52.029 & $(+14.50 \%)$ \\
\hline & II & 57.906 & 61.086 & $(+5.21 \%)$ \\
\hline \multirow[t]{2}{*}{ November } & I & 0 & 18.901 & $(+100 \%)$ \\
\hline & II & 35.958 & 31.217 & $(-13.18 \%)$ \\
\hline \multirow[t]{2}{*}{ Desember } & I & 16.852 & 10.365 & $(-38.49 \%)$ \\
\hline & II & 0 & 38.421 & $(+100 \%)$ \\
\hline Total & & 802.071 & 767.297 & $(-4.34 \%)$ \\
\hline
\end{tabular}

Berdasarkan perhitungan berikut pada DI Kajar 2G mengalami kenaikan kebutuhan air, luasan areal sawah berkurang, dan ada beberapa kerusakan disaluran.

\section{Kesimpulan}

Berdasarkan hasil perbedaan luas area sawah pada tahun 2012 semua Daerah Irigasi mengalami penurunan pada tahun 2017. Berdasarkan hasil Inventarisasi kondisi eksisting sistem jaringan beberapa saluran pada setiap Daerah Irigasi ada yang mengalami kerusakan dan ada yang masih berfungsi dengan baik. Berdasarkan perhitungan kebutuhan air jika dibandingkan pada tahun 2012 dan 2017 pada DI Kajar 2D, 2E, dan 2F mengalami 
kenaikan kebutuhan air pada tahun 2017, sedangkan pada DI Kajar 2G mengalami penurunan pada tahun 2017. Berdasarkan perhitungan hasil selisih efisiensi penggunaan kebutuhan air pada DI Kajar 2D sebanyak 13 periode mengalami kenaikan, 2E sebanyak 15 periode mengalami kenaikan, $2 \mathrm{~F}$ sebanyak 18 periode mengalami kenaikan, sedangkan pada $2 \mathrm{G}$ mengalami penurunan sebanyak 19 periode.

\section{Daftar Pustaka}

[1] Anonim. Peraturan Menteri Pekerjaan Umum Nomor 23/PRT/M/2015 tentang Pengelolaan Aset Irigasi. Jakarta: Departemen Pekerjaan Umum. (2015).

[2] Anonim. Peraturan Menteri Pekerjaan Umum Nomor 32/PRT/M/2007 tentang Pedoman Operasi dan Pemeliharaan Jaringan Irigasi BAB I Ketentuan Umum Pasal 1 ayat 5. Jakarta: Departemen Pekerjaan Umum. (2007).

[3] Anonim. Kecamatan Lowokwaru Dalam Angka 2017. https://malangkota.bps.go.id/publication/2017/10/09/6d224e05bf989025e6540f71/ke camatan-lowokwaru-dalam-angka-2017.html. (2017).

[4] Prahasta, Eddy. Sistem Informasi Geografis. Informatika Bandung. (2002).

[5] Prahasta, Eddy. Sistem Informasi Geografis. Informatika Bandung. (2007).

[6] Anonim. Standar Perencanaan Jaringan Irigasi KP-01, KP-02, KP-03, KP-04, KP-05, KP-06 DAN KP-07. Bandung : Ditjen Pengairan Dep. PU Galang Persada. (1986).

[7] Soemarto. Hidrologi Teknik. Surabaya: Usaha Nasional. (1987).

[8] Limantara, Montarchi. Hidrologi Praktis. Bandung: Lubuk Agung. (2010).

[9] BR, Sri Harto. Analisi Hidrologi. Jakarta: Gramedia Pustaka Utama. (1993).

[10] Satria Sebayang, Muhammad., Sumono., Putra Munir, Achwil. Evaluasi Kinerja Operasi dan Pemeliharaan Sistem Irigasi Medan Krio di Kecamatan Sunggal Kabupaten Deli Serdang. E-Jurnal. Vol. 2 No.3 Tahaun 2014. (2014). 